\title{
Undergraduate Classification and Management Method Guided by Students' Ability and Quality
}

\author{
Ding Gang ${ }^{1,2}$, Wei Lihong ${ }^{1}$, Cheng Yanyu ${ }^{1}$ \\ ${ }^{1}$ Harbin Institute of Technology Office of Academic Affairs, Harbin City, China \\ ${ }^{2}$ Harbin Institute of Technology School of Mechatronics Engineering, Harbin City, China
}

\section{Email address:}

dinggang@hit.edu.cn (Ding Gang), weilihong@hit.edu.cn (Wei Lihong), chyy@hit.edu.cn (Cheng Yanyu)

\section{To cite this article:}

Ding Gang, Wei Lihong, Cheng Yanyu. Undergraduate Classification and Management Method Guided by Students' Ability and Quality. Science Innovation. Vol. 6, No. 3, 2018, pp. 118-122. doi: 10.11648/j.si.20180603.11

Received: April 17, 2018; Accepted: June 5, 2018; Published: June 22, 2018

\begin{abstract}
There will be individual differences between students in terms of ability and quality. Teachers, teaching management staff and workers in charge of students' affairs should be aware of and recognize the differences in ability and quality of each student in the teaching and management work, and then carry out teaching and management according to the specific characteristics of each student. For this reason, this paper puts forward a kind of student classification method based on ability and quality oriented learning achievement, and gives suggestions on education and management according to the characteristics of different categories of students. In order to realize Student - centered by teaching students in accordance with their aptitude, and then the quality of talent training can be improved greatly.
\end{abstract}

Keywords: Ability and Quality, Teaching Students in Accordance of Their Aptitude, Student - Centered, Quality of Talent Training

\section{以能力和素质为导向的学生分类与管理方法}

\section{丁刚 ${ }^{1}{ }^{2}$, 魏立红 ${ }^{1}$, 程彦宇 ${ }^{1}$}

1教务处, 哈尔滨工业大学, 哈尔滨市, 中国

${ }^{2}$ 机电工程学院, 哈尔滨工业大学, 哈尔滨市, 中国

\section{邮箱}

dinggang@hit.edu.cn(丁刚), weilihong@hit.edu.cn(魏立红), chyy@hit.edu.cn(程彦宇)

摘要：学生之间在能力与素质方面难免会存在个体差异。任课教师、教学管理工作人员和学生工作者在教育教学和管 理工作中须意识并认识到每名学生在能力和素质方面的不同, 然后须根据每名学生的具体特点开展教学和管理工作。 为此, 本文提出了一种以能力和素质为导向以学习成绩为参考的学生分类方法, 并根据不同类别学生的特点给出了开 展教育教学和管理工作的建议。因材施教才能真正做到“以学生为中心”, 进而能够大幅提高人才培养质量。

关键词：能力与素质, 因材施教, 以学生为中心, 人才培养质量 


\section{1. 引言}

由集合中元素的的确定性、无序性、互异性[1]，同时 考虑到中国目前的高考制度以及基础教育和高等教育的 现实, 大学本科生之间在能力和素质等方面必定会存在一 定程度的差异。这些差异的存在应当引起广大教学管理工 作人员、学生工作者和任课教师的高度重视 $[2,3]$ 。因人而 异有针对性地开展教育教学和管理工作, 才能收到事半功 倍持续提高人才培养质量的效果。

目前, 中国很多高校正在深入贯彻落实“以学生为中心, 学生学习与发展成效驱动”的教育教学理念 [4]。这一教育教 学理念要想得到真正实施, 就必然要求从过去高度甚至是 过分重视学生的学习成绩, 转向更加重视学生的综合素质 和创新实践能力的培养, 构建核心价值塑造、综合能力养 成、多维知识探究“三位一体”的新人才培养模式。

在群体教育中要实现“以学生为中心”是非常困难的 [5], 这就要求教学管理人员、教师、学生工作者等相关人 员必须具体问题问题具体分析, 不能采取“一刀切”的简单 的管理方式。目前, 在一线的教学和管理工作中, 部分教 学管理工作人员、学生工作者和任课教师还尚未能深刻理 解“以学生为中心, 学生学习与发展成效驱动”的教育教学 理念, 在日常的学生管理工作中, 仍会按照“一刀切”的惯 性思维陷入一个按成绩高低对学生进行分类评价并以此 为依据开展教育教学和管理工作的误区。

成绩高低固然重要, 因为成绩确能从一个侧面反映学 生的学习态度及其能力和素质。但也要清醒地认识到, 成 绩并不能完全反映一个学生的综合能力与素质。例如, 有 些本科生其在读期间学习成绩平平，但毕业多年后其事业 却红红火火。这种现象的存在, 使部分教学管理工作人员、 学生工作者和任课教师在回答学生关于“为何有的学生在 学习阶段其成绩一般, 但是毕业踏入社会以后他们却能开 创一番事业? 而有些学生, 尽管在校期间其成绩很高, 但 是毕业踏入社会以后他们却表现平平? ”这些问题的时候 感觉颇为为难。有些学生甚至会直接问: “老师, 成绩真 的那么重要吗? 学生只考个及格难道不行吗? ”个别教学 管理工作人员、学生工作者和任课教师在解释这些问题的 时候, 总是会跟学生讲一番大道理, 强调学习的重要性, 尤其强调如果成绩不高则会丧失免试推荐攻读硕士研究 生的机会等等。这样的解释有些牵强、空洞, 如果学生四 年或五年的本科学习不以攻读硕士研究生为目标难道不 可以吗? 对于这些学生又该如何解释上述问题, 让他们觉 得能够接受从而端正学习态度好好学习呢? 尤其是目前 在校的本科生已经以“90后”为主, 且“ 00 后”也开始迈入大 学校园, 这些学生的个性更强、思维更活跃, 他们通过互 联网与社会接触更多, 对社会的了解也更多[6,7]。如何在 这种新形势下找到行之有效的教育教学和管理工作方法 做好学生管理工作值得进一步思考。

\section{2. 基于能力和素质的学生分类方法}

随着“以学生为中心, 学生学习与发展成效驱动”的教 育教学理念在中国高校的深入贯彻落实, 新型人才培养的
指挥棒将会从“成绩”向“素质”和“能力”逐渐转移，教师和 学生乃至整个社会都将会逐渐接受、适应这种转变。

考虑到学生毕业后在社会或产业、行业的发展规律, 以及当代大学生的特点, 本文尝试以能力和素质为导向以 学习成绩为参考将学生大致划分为五类, 并按照每类学生 的特点提出有针对性的开展学生教育教学和管理工作的 建议。

第一类学生, 能够主动观察问题、深入思考问题、全 面分析问题、自主解决问题，对于毕业后的去向有明确的 志向, 并且勤奋, 学习成绩优秀。

例如, 有的中国高校的本科生在就读本科期间就能够 在《Nature》等国际顶尖期刊上以共同第一作者的身份发 表高水平科研论文 [8,9]; 有的学生在创新的基础上完成了 创业，进入了福布斯中国“30位30岁以下精英”榜单，成为 中国大学生创新创业的典范[10]。

第二类学生, 总体上基本能够主动观察问题、深入思 考问题、全面分析问题、自主解决问题，对于毕业后的去 向稍微模糊一些, 不是特别勤奋, 学习成绩一般介于良好 和中等之间。

此类学生在参加工作以后, 一般能够结合所在的产业 或行业灵活运用所学知识解决相关复杂工程问题, 较好地 达到了高校的培养目标和毕业要求, 既具有创新精神和意 识, 又具有比较强的实践动手能力。此类学生在工作初期 就会在工作中崭露头角, 受到用人单位的欢迎和好评。

第三类学生, 在主动观察问题、深入思考问题、全面 分析问题、自主解决问题方面有所欠缺, 但对于毕业后的 去向较为明确, 一般追求免试推荐攻读硕士研究生或考取 硕士研究生, 死记硬背或生搬硬套的能力较强, 学习勤奋, 学习成绩一般为优秀。

很多用人单位对此类学生的评价一般是“高分低能”。 此类学生也可能会成为高校开展相关教育综合改革、教学 方法和考试方法改革的阻力。

第四类学生，基本上做不到主动观察问题、深入思考 问题、全面分析问题、自主解决问题，对于毕业后的去向 也较为模糊, 死记硬背或生搬硬套的能力一般, 学习不太 勤奋, 学习成绩一般介于中等和及格之间。

第五类学生，做不到主动观察问题、深入思考问题、 全面分析问题、自主解决问题, 对于毕业后的去向很模糊, 死记硬背或生搬硬套的能力不足, 学习不勤奋, 学习成绩 一般介于及格和不及格之间, 通常以不及格居多。

中国高校为保障人才培养质量底线,一般都会根据本 校实际结合教育部的规定 [11], 制定本校的“学生学业成绩 未达到学校要求予以退学”的相关规定。此类学生若无针 对性学业帮辅或者其本人不接受学校提供的学业帮辅, 则 往往会因学业成绩未达到学校要求而被退学。

\section{3. 学生管理方法}

对于第一类学生, 其学习效率较高, 不仅能保质保量 地完成任课教师布置的课内及课外作业, 而且能够举一反 三, 触类旁通。此类学生一般占当届学生总数的不到 $5 \%$ 。 对于此类学生, 任课教师应注意引导其扩展视野, 向其详 
细介绍本专业相关科研工作国内外的最新进展, 并为其参 加各类大学生科技创新创业活动提供条件和支持; 教学管 理工作人员和学生工作者可根据此类学生的性格等特点, 积极鼓励此类学生争取担任学生会干部、班长、团支书、 学习委员等学生干部职务, 通过此类学生的榜样作用带动 整个班级乃至整个年级的学习风气。

对于第二类学生, 由于不像第一类学生那样勤奋, 因 此其学习效率一般, 对于自己感兴趣的课程能够保质保量 地完成任课教师布置的课内及课外作业, 对于自己兴趣不 高的课程, 则可能会采取糊弄的态度, 从而在主动观察问 题、深入思考问题、全面分析问题、自主解决问题方面与 第一类学生有一定的差距。这类学生对于学习的态度其功 利性较淡, 较为看重个性化发展, 不太注重学习成绩的高 低。此类学生一般占当届学生总数的不到 $10 \%$ 。对于此类 学生, 任课教师应注意以丰富的社会与生产案例以及课堂 上较为充分的师生互动引导其建立对于课程学习的兴趣, 并鼓励其积极参与各类大学生科技创新创业活动; 教学管 理工作人员和学生工作者可根据此类学生的性格等特点, 积极鼓励此类学生多参与各类社会实践活动, 为其将来走 向社会打下良好的基础。

对于第三类学生, 由于其学习带有明显的功利色彩, 因此注定在此类学生心目中学习成绩高于一切。对于免试 推荐攻读硕士研究生有加分等优惠政策的各类大学生科 技创新创业活动其或许能够参加, 但其对于免试推荐攻读 硕士研究生没有加分的项目及活动则往往提不起兴趣。对 于直接参与平均学分绩计算的必修课程其学习态度较为 认真, 对于其他选修类课程则可能兴趣不高甚至可能会以 及格为追求目标。此类学生一般占当届学生总数的不到 $15 \%$ 。对于此类学生, 任课教师教学中要竭力避免照本宣 科, 而且在设计作业或试卷时, 应力求避免通过死记硬背 或生搬硬套就能获得高分的题目, 应通过科学的作业或试 题引导此类学生转变学习态度, 转变到真正理解知识、灵 活运用知识的层次上来; 由于此类学生非常注重遵守学校 的校规校纪和其他各项管理规定, 加之其学习成绩也较为 突出, 因此在教学管理工作人员和学生工作者中会形成一 个认识误区, 即认为这部分学生是“好学生”, 从而放松对 此类学生的管理。实际上这一类的学生其承受挫折的能力 往往较弱, 反而应当是学生管理工作的一个重点, 教学管 理工作人员和学生工作者应有意识地加强对此类学生抗 挫折能力的训练, 并应与任课教师一道引导其多参与各类 实习和实践锻炼, 有意识地使其认识到理论与实践相结合 的重要性。

对于第四类学生, 由于其对学习的主观能动性不强, 也不掌握大学阶段的学习方法, 因而对于学习不甚重视, 难以做到课前预习课后复习, 往往会对任课教师布置的 课内和课外作业采取糊弄的态度, 有时甚至还会大量抄 袭别人的作业和实验报告等; 同时, 对于上课出勤也不 重视, 迟到、早退甚至旷课的现象时有发生, 有时即使 上课出勤也 “出工不出力”, 不认真听讲，上课期间思想 容易开小差, 听课效率较低, 久而久之由于跟不上任课 教师的思路从而丧失对课程的学习兴趣。此类学生一般 占当届学生总数的 $60 \%$ 左右。对于此类学生, 任课教师 课上课下都要加强管理, 对其严格要求, 对其作业抄袭、
迟到、早退、旷课等不良行为等应及时提出严厉批评, 断绝其蒙混过关、得过且过的念头; 当然, 在严加管理 的同时, 也应注意加强对此类学生学习兴趣的保护, 对 于主动找教师答疑或交流的学生, 教师应保持最大的热 情, 通过耐心细致的讲解拉近其与教师的距离, 激发其 学习兴趣。对于此类学生, 教学管理工作人员和学生工 作者应注意加强与任课教师的配合, 既加强管理又要调 动和保护其学习兴趣。

对于第五类学生, 由于其对学习基本丧失兴趣, 因而 很难激发出其对学习的热爱。此类学生一般占当届学生总 数的不到 $10 \%$ 。对于此类学生, 其管理重点不在于任课教 师, 而在于教学管理工作人员和学生工作者。教学管理工 作人员要根据本校的实际情况制定出较为严格的过程淘 汰制度, 对于不适合继续在大学进行学习的学生要及时予 以预警, 对于预警无效而又达到退学红线的学生要顶住一 切压力予以清退, 以做效尤。学生工作者要关注此类学生 人生观、世界观和价值观的转变, 在工作中既动之以情又 晓之以理, 本着为教育事业高度负责的精神, 不以有色眼 镜看待这些学生, 尽一切努力关心和支持这些学生的成长 和发展, 促使其能够通过自身的学习顺利毕业; 对于不能 顺利毕业的学生要做好其思想工作, 使其认清社会现实, 以保证使其在社会中吸取其自身在校学习期间的教训, 走 好人生以后的每一步。

\section{4. 基于因材施教开展教学方法和考试方法改革}

在开展教学方法和考试方法改革的过程中, 高校要高 度注意“两头”即第一类和第五类学生。对第一类学生要给 予其宽广的学术和科研舞台。例如, 哈尔滨工业大学积极 鼓励并大力支持学生创新创业, 由学生团队完成了“紫丁 香一号”“紫丁香二号”两颗小卫星的研制和发射后的卫星 管控工作, 成全国之首 $[12,13]$ 。对第五类学生, 哈尔滨工 业大学近年来持续加强对学习困难学生的学业帮辅工作 [14], 成效显著, 应届本科毕业生的结业率和“学生学业成 绩未达到学校要求予以退学”本科生数量实现了双下降。

传统的“以教师为中心”的课堂教学, 除了灌输式教学、 不重视引导学生讨论探究这些缺点以外, 还有一个很大的 特点那就是由于教师和学生是“一对多”的关系, 所以在同 一间教室、同一堂课上, 教师很难照顾到所有类型学生的 不同需求。对教师而言, 同样的授课内容、授课方式, 对 于第一类和第二类学生而言可能会觉得授课进度过慢、内 容过于简单, 而对于第四类和第五类学生而言则可能正好 相反, 可能会觉得教师的讲课速度过快、内容多且难以马 上接受或理解。如何才能实现“以学生为中心”的“因材施 教”值得授课教师思考。

中国古代著名的思想家和教育家孔子曾经说过: “有 教无类”。孔子所说的“类”主要是指“阶级”, 与本文所提出 的分类并非同一含义, “有教无类”是指无论人的出身贫富、 贵贱其都应有接受教育的权利和机会。孔子也是最早采用 “因材施教”这一教学方法的教育家之一 [15]。时至今日, 因材施教仍然是各级各类教学中广泛采用的一项重要的 教学方法。根据学生自身能力和素质的不同, 任课教师、 教学管理工作人员和学生工作者可以因材施教, 有针对性 
的进行各项教育教学和管理工作, 尽最大可能发挥学生的 长处同时弥补其不足, 从课堂教学、创新创业实践和社会 实践等角度出发, 想尽一切办法激发学生的学习兴趣, 树 立学生学习的信心, 从而促进学生能力和素质的全面综合 发展。

为达上述目标, 哈尔工业大学自2010年起持续推进以 “三个废除”为核心的教学方法和考试方法改革, 即废除一 张考卷定成绩, 推行累加式考试方法改革, 注重对学生学 习过程和能力与素质的全面考察; 废除照本宣科灌输式教 学, 积极推行启发式、互动式教学方法; 废除千篇一律的 实验实习, 开放实验室 $[16,17]$ 。近年来, 哈尔滨工业大学 还大力开展在线开放课程建设, 并提出了“MOOC+SPOC+ 翻转课堂”混合式教学模式, 依托信息化与教育教学的全 面深度融合, 不断开展教学方法和考试方法改革, 关注学 生学习与发展成效, 促进了学生的自主学习和深度学习 $[18,19]$ 。

这些改革措施, 深入贯彻落实了“以学生为中心, 学 生学习与发展成效驱动”的教育教学理念, 改变了学生以 “成绩”为指挥棒的传统学习模式, 对于提高学生的实践能 力和创新能力发挥了重要作用[20]。

\section{5. 结论}

从深入贯彻落实“以学生为中心, 学生学习与发展成 效驱动”的教育教学理念入手, 本文通过依据学生自身的 能力和素质对学生进行类别划分, 然后根据各类学生的具 体特点因材施教。由上述所介绍的以能力和素质为导向以 学习成绩为参考的学生分类标准可以看出, 第一类和第二 类学生由于其能力和素质较为综合全面, 因而尽管第二类 学生的学习成绩比照第三类学生稍差一些, 但是在走向社 会或工作岗位以后, 第一类和第二类学生的发展往往很有 可能会好于第三类学生。这也许能够解释前文所提出的一 个问题——为什么有的学生在学习阶段其成绩一般, 但是 毕业踏入社会以后他们却能开创一番事业。

以上分类方式与高校目前倡导建立的多维知识探究、 核心价值塑造、综合能力养成“三位一体”的新人才培养模 式是相对应的, 可供相关任课教师、教学管理工作人员和 学生工作者参考, 只要能在教育教学和管理工作中意识及 认识到每个学生在能力和素质等各方面的差异, 然后针对 不同类别学生的具体特点因材施教, 就会使学生获益, 从 而能够提高学校的人才培养质量。

\section{致谢}

本文在黑龙江省高等教育教学改革研究重点项目“面 向优质教育资源传播与共享的学分转换机制的研究与实 践” (项目编号: SJGZ20170068) 、黑龙江省高等教育教 学改革研究一般项目 “MOOC选用的问题分析与对策研究” (项目编号: SJGY20170663)、教育部在线教育研究中 心重点项目“基于MOOC的教育资源建设和增益传播的理 论与实践研究”资助下完成。

\section{参考文献}

[1] 杨骁睿. 论集合中的元素的确定性、互异性和无序性[J]. 数 码世界,2017,7:274。

[2] 郑俊玲.高校辅导员对学生分类管理、分向培养的实施以河北科技师范学院为例 [J]. 产业与科技论坛, 2016, 15(4):155-156。

[3] 王楠.我国高校学生管理模式的若干思考[J].课程教育研 究,2018,12:177-188。

[4] 沈毅,宁永臣,邹萍.哈佛大学教学方法的隐性理论基础:问题 元理论[J].黑龙江高教研究,7: 70-73。

[5] 李培根. 以学生为中心的教育:一个重要的战略转变 [J]. 高等 工程教育, 2011,13:8-9。

[6] Ding Gang, Zhang Yangyang. Research on MOOC domestic learning user groups. Science Innovation, 2017, 5(1):38-43.

[7] 杨帆.浅议 90 后大学生的特点及其产生的社会背景[J].中国东盟博览, 2011(5):134-135。

[8] De Dong, Kuan Ren, Xiaolin Qiu, etc. The crystal structure of Cpf1 in complex with CRISPR RNA. Nature, 2016, 532: $522-526$.

[9] Rao Feng, Ding Keyuan, Zhou Yuxing, etc. Reducing the stochasticity of crystal nucleation to enable sub-nanosecond memory writing[J]. Science, 2017, 358 (6369):1423。

[10] 福布斯中国. 2017 福布斯中国30位30岁以下精英排行榜 [EB/OL]. http://top.askci.com, 2018-04-28。

[11] 中华人民共和国教育部. 普通高等学校学生管理规定 [EB/OL].

http://www.moe.edu.cn/srcsite/A02/s5911/moe_621/201702/t 20170216_296385.html, 2018-04-28.

[12] 哈尔滨工业大学.我校“紫丁香二号”卫星成功发射学生自主 研发尚属国内首例 [EB/OL]. http://news.hit.edu.cn/72/39/c1510a94777/page.htm 2015-09-20.

[13］哈尔滨工业大学.我校学子自主研发的第二颗卫星“紫丁香 一号”成功发射 $[\mathrm{EB} / \mathrm{OL}]$.

http://news.hit.edu.cn/b2/60/c1510a176736/page.htm, 2017-04-19.

[14] 哈尔滨工业大学.不让一个学生掉队我校合力做好学业帮 辅“大文章”[EB/OL].

http://news.hit.edu.cn/06/5f/c1510a198239/page.htm, 2018-01-14.

[15] 汪开栋.因材施教成就向心力[J].班主任, 2018, 3: 49-50.

[16] 周玉,齐晶瑶.全球化视野下的教学改革和教育创新一一哈 工大工程教育策略与实践研究 [J].高等工程教育研究, 2013, 3: $1-7+45$ 。

[17] 周玉,丁雪梅 沈毅,等.适应时代发展,培养工程科技创新人 才 $[\mathrm{C}]$. 提升高等学校教育质量的实证研究 (上册), 2016:1-6。 
[18] 徐晓飞,傅育熙,李廉,等. 关于我国计算机教育MOOC发展 的思考 [J].中国大学教学, 2015,11:6-10+30。

[19] 战德臣.“大学计算机”“MOOC+SPOCs+翻转课堂”混合教学 改革实施计划 $[J]$.计算机教育,2016,1:12-16。
[20] 鲁佳,白雪. 高校大学生创新创业能力培养研究一一哈尔 滨工业大学航天学院为例. 黑龙江教育 (理论与实 践),2016,12:1-2。 